From the Department of Pharmacology, Medical School, University of Indonesia, Jakarta.

\title{
A Case of Paratyphoid Fever Accidentally \\ Treated with Amoxycillin \\ (Case Report)
}

by

\section{DARMANSJAH}

\section{Introduction}

Salmonellosis can be treated by a wide variety of antibiotics. At least some 15 antibiotic preparations show inhibition in vitro of Salmonella strains, when result of laboratory sensitivity tests is received.

Clinically however, treatment of typhoid and paratyphoid fever consists of chloramphenicol or some other secondary choice of antibiotics.

In general the choice of antibiotic cannot be solely determined by sensitivity tests in vitro. Antibiotic concentrations at the site of organ involvement in disease-states, unbound fractions of antibiotics and plasticity of bacteria (Slamet Djais and Uyka Slamet Santoso, 1971) are important factors ito be considered. The final decision on which antibiotic to be used must lie with the physician's clinical judgement based on sound clinical trials.
A case of paratyphoid-fever is reported below which responded dramatically to $6(\mathrm{D}(-) \propto$-Amino-pHydroxyphenyl acetamido) - Penicillanic acid or amoxycillin, known in Indonesia under the trade name of Amoxil (250 mg capsules).

\section{Case Report}

T, a 12-year-old boy, weighing 32 $\mathrm{kg}$ presented himself on March 8, 1974 with fever, cough and rhinitis of 1 day duration at the private practice office of the author. No important clinical findings were noted and the patient was treated symptomatically with anti-influenza drugs.

On the 12th of March the patient came back with an additional throbbing headache while fever lasted, for which still no antibiotic treatment was given.

On the 15th, bronchitis and marked prostration were noted and amoxycillin was given at a dose of 3 times 
$250 \mathrm{mg}$ per day. The next day fever subsided and cough with general malaise diminished progressively.

On the 18th of March the patient felt well enough to go to school and the parents stopped the antibiotic treatment.

On the 20th high fever again struck the boy, and amoxycillin treatment was reinstituted.

Prompt after 2 days the patient became afebrile and felt much better again.

Laboratory results on the 14th of March showed no leucopenia (7200), $2 \%$ eosinophils, sedimentation rate of 36 in the first hour (Westergren), no urine changes. Malaria parasites were not found, and Widal was negative.

It was on the 23rd March, three days after the second febrile period that the bloodculture report was received which revealed positive Salmonella Parathyphus A.

Since the patient was clinically improved at that time there was no point for hospitalization.

Amoxycillin treatment was prolonged 8 days after fever went down.
No complications or sequelae, nor side effects were noted, though the patient violated warnings to keep absolute rest in bed.

Bloodculture was repeated on the 25th of March which became negative, whereas the Widal agglutination test showed a definite rise, notably titer $\mathrm{H}: 1 / 800$ and titer $\mathrm{O}: 1 / 100$.

Stoollculture was not done.

\section{Discussion}

There is a few literature on typhoid fever treatment with amoxycillin. Farid et al. (1974) reported from Cairo the succesful treatment of 7 typhoid and paratyphoid adult patients with a dose of $3 \times 500 \mathrm{mg}$ of amoxycillin continued for 7 days after the afebrile period.

The period in which the patients became afebrile varied from 2 to 10 days but the clinical improvement (disappearance of toxicity, abdominal distention, coated tongue and headache) was more rapid.

In the search for other drugs than chloramphenicol in the treatment of typhoid fever, further trials with amoxycillin are seemingly warranted to establish its usefulness. 


\section{REFERENCES}

1. FARID, Z., SIPPEL, J.E., HASSAN, A. and TRABOLSI, B.: Treatment oi acute enteric fever with amoxycillin. The Lancet iii : 350 (1974).

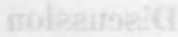

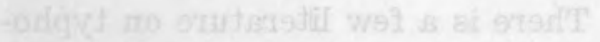

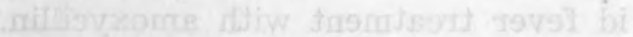

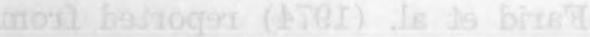

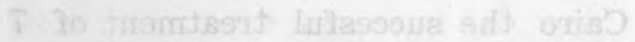

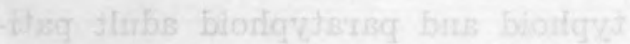
to gert 000 $x$ \& 70 saob \& divin atro

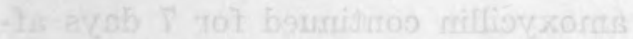

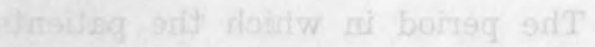

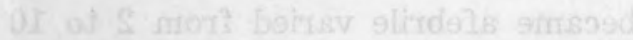

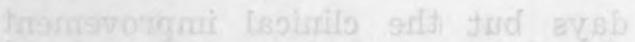

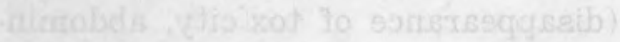

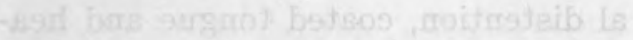
Wighes gromi aum (antesit

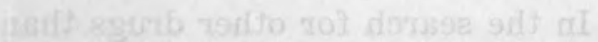

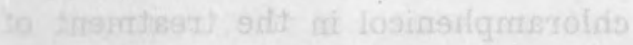

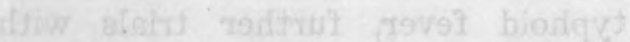

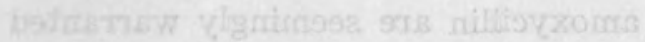

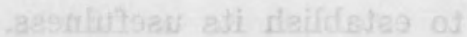

2. SLAMET DJAIS and UYKA SLAMTET SANTOSO: Hubungan percobaan resistensi dengan terapi antibiotika, Maj. Kedok. Indones. 21 : 308 (1971).

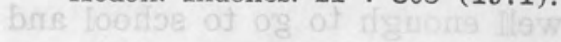

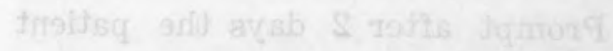

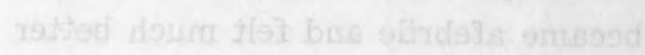
atisigng

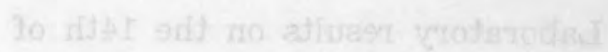

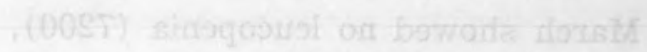

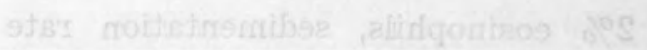

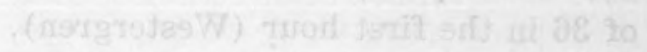

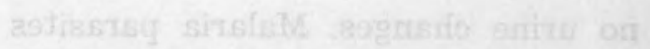

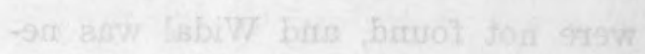

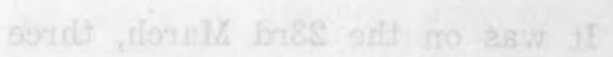

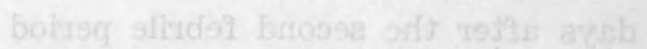

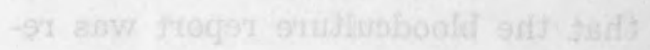

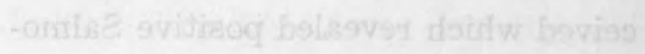
A. malquilstas nilon

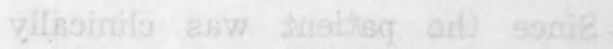

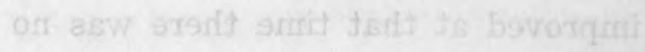

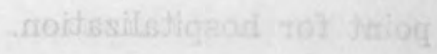

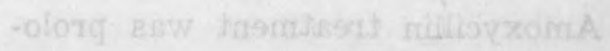

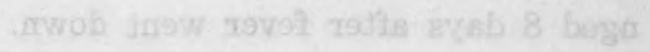

